\title{
PET Oligomer Waste to Modify CAP Characteristics
}

\section{C. Mendes", M. L. Dias, P. S. C. Pereira, L. M. R. Albuquerque}

Centro de Tecnologia, Instituto de Macromoléculas Professora Eloisa Mano-IMA, Universidade Federal do Rio de Janeiro-UFRJ, Rio de Janeiro, Brazil.

Email: *1cmendes@ima.ufrj.br

Received May $16^{\text {th }}, 2012$; revised June $10^{\text {th }}, 2012$; accepted July $12^{\text {th }}, 2012$

\begin{abstract}
To develop an improved method of reusing poly(ethylene terephthalate) (PET) waste in the production chain, it was chemically modified with pentaerythritol (PENTE), resulting in PET/PENTE (60/40) oligomer. This was added to petroleum asphalt cement (CAP) in different proportions - 5, 10 and $20 \mathrm{wt} \%$ - as a modifier of bitumen characteristics. The mixture was evaluated by thermogravimetry (TG/DTG), differential scanning calorimetry (DSC), infrared spectroscopy (FT-IR), optical microscopy (OM) and the adhesion-peel test. The oligomer enhanced substantially the asphalt thermal stability- $T_{\text {onset. }}$ OM images showed strong compatibility between components and PET's amorphization. PET oligomer increased CAP's wettability and the mixture presented cohesive fracture through the peel test. The mixture has excellent potential as paving material.
\end{abstract}

Keywords: PET Waste; Pentaerythritol; CAP; Recycling

\section{Introduction}

In recent years, the growing use of polymers in everyday products has generated an enormous amount of municipal solid waste. This has brought many environmental problems. In general, these wastes take long time to undergo spontaneous degradation and release toxic gases if they are burned $[1,2]$. The majority of discarded polymer materials are from packaging. Taking into account the huge potential of plastics and the problems caused by pollution from waste, there is a growing worldwide trend to recycle them [3]. When reused, PET packages show several advantages - lower consumption of water and energy and environmental and social benefits, among others [4]. Waste disposal is a main concern of society, prompting actions by industry and research centers [5-7]. Recently, an article on PET waste oligomerization through the action of polyfunctional alcohol — pentaerythritol was published [8].

Polymers have been studied as modifiers of asphalt mainly to overcome some deficiencies of asphalt cement and to improve its properties, such as reducing permanent thermal deformation and cracking. As modifier agents, polymers are compatible and increase asphalt degradation at high temperatures. The asphalt's characteristics as well as the type and amount of polymer have a large influence on the appropriate asphaltic mixture $[9$, $10]$.

\footnotetext{
${ }^{*}$ Corresponding author
}

Asphalt cement can be formed naturally, through evaporation of surface oil deposits, but the majority comes from the heavy fraction of petroleum from distillation at refineries. Petroleum asphalt cement (CAP) consists of 90\% - 95\% hydrocarbons - saturated and aromatic - and $5 \%-10 \%$ of structures with hetero atoms (oxygen, sulfur, nitrogen) and metals, such as vanadium, nickel and iron. Brazilian CAPs have low sulfur and metals content but high levels of nitrogen. Asphaltenes and maltenes are the main asphalt components. They are complex mixtures consisting of condensed aromatic rings, resins and saturated and aromatic compounds. The ratio between asphaltenes and maltenes has a significant effect on asphalt performance [11-14]. The reuse of plastics as additives for CAP increases the possibility of using urban plastic waste in the productive chain $[15,16]$.

This work intended to develop a new material from plastic arising from municipal solid waste. The discarded PET was oligomerized by a polyfunctional alcohol. The PET oligomer was mixed with CAP in different proportions to evaluate its influence on the CAP's thermal, adhesive and morphological characteristics.

\section{Experimental}

\subsection{Materials}

Flakes of poly (ethylene terephthalate) (PET) waste with $24 \%$ crystallinity degree were supplied by CPR Ltd. (Rio de Janeiro, Brazil). Commercial pentaerythritol, here 
called PENTE, was provided by S. A. Degussa (São Paulo, Brazil). Commercial zinc acetate produced by J. T. Baker was used without further purification. The asphalt cement was from a refinery.

\subsection{Oligomer Preparation}

This measurement and others are deliberate, using specifications that anticipate your paper as one part of the entire proceedings, and not as an independent document. Please do not revise any of the current designations. The PET/PENT (60/40) blend containing $0.5 \mathrm{wt} \%$ zinc acetate catalyst was prepared by melt processing in an Haake Rheomix 600 internal mixer, at $250^{\circ} \mathrm{C}, 60 \mathrm{rpm}$, for 10 minutes. Before processing, PET flakes were previously dried at $120^{\circ} \mathrm{C}$, for 4 hours [8].

\subsection{CAP/Oligomer Mixture}

The mixture of CAP with PET/PENTE oligomer in different oligomer proportions $(5,10$ and $20 \mathrm{wt} \%)$, called CAP (95/5), CAP (90/10) and CAP (80/20), respectively, was prepared in a $500 \mathrm{~mL}$ glass flask, at $180^{\circ} \mathrm{C}$, with mechanical stirring $(600 \mathrm{rpm})$ for 2 hours.

\subsection{Thermogravimetry and Derivative Thermogravimetry (TG/DTG)}

The TG/DTG curves were obtained by a TA thermoanalyzer (Q500) by heating the sample from $30^{\circ} \mathrm{C}$ to $700^{\circ} \mathrm{C}$ at a heating rate of $10^{\circ} \mathrm{C} \cdot \mathrm{min}^{-1}$ under nitrogen atmosphere. The onset temperature ( $\mathrm{T}_{\text {onset }}$ ), maximum degradation temperature $\left(T_{\max }\right)$ and end temperature $\left(\mathrm{T}_{\text {end }}\right)$ were determined.

\subsection{Differential Scanning Calorimetry (DSC)}

Calorimetric measurements were carried out in a TA calorimeter (Q1000). The sample was heated from $-20^{\circ} \mathrm{C}$ to $100^{\circ} \mathrm{C}$ at a heating rate of $10^{\circ} \mathrm{C} \cdot \mathrm{min}^{-1}$ under nitrogen atmosphere (first scan), kept for $2 \mathrm{~min}$ to erase the thermal history, and then cooled to $-20^{\circ} \mathrm{C}$ at the maximum (second scan). A second heating cycle (third scan) was performed with the same protocol as the first scan. The variation in the baseline was evaluated considered the PET glass transition temperature, $\mathrm{T}_{\mathrm{g}}$, and CAP thermal transition temperature [17-19].

\subsection{Morphological Analysis}

The morphology was analyzed under a Zeiss model THMS 600 microscope from squeezed film between two glass slides. The assembly was inserted into the microscope in the hot stage and heated from $25^{\circ} \mathrm{C}$ to $280^{\circ} \mathrm{C}$, where it was kept for 2 minutes to eliminate the thermal history. After that, the cooling was performed until $25^{\circ} \mathrm{C}$.
The morphology of the matrix and dispersed phase was monitored by taking photographs.

\subsection{Peel Test}

The adhesive characteristic of the asphaltic mixture was evaluated based on the ASTM D1876 standard [20]. The material was poured between aluminum plates with constant thickness and the assembly was taken for peeling in an Instron machine. The force of peeling was registered and then test photos were taken to evaluate what kind of fracturing-adhesive or cohesive had occurred.

\section{Results and Discussion}

\subsection{Thermogravimetry and Derivative Thermogravimetry (TG/DTG)}

Figures $\mathbf{1}$ and $\mathbf{2}$ show the degradation and first derivative curves of the materials, respectively. Table 1 contains the $T_{\text {onset }}, T_{\max }$, and $T_{\text {end }}$ degradation temperatures and amount of residue. The PET/PENT 60/40 blend presented three degradation steps. The first one was located at $100^{\circ} \mathrm{C}-175^{\circ} \mathrm{C}$ and it was attributed to the absorbed water. The next one occurred at $250^{\circ} \mathrm{C}-325^{\circ} \mathrm{C}$, caused by the unreacted pentaerythritol. The final step, at $325^{\circ} \mathrm{C}$ $-525^{\circ} \mathrm{C}$, was the result of the degradation process of the PET/PENTE oligomers.

The CAP's curve shows a unique degradation step pattern. Concerning the mixture CAP/oligomer, all of them presented one stage of degradation. The $\mathrm{T}_{\text {onset }}$ and $\mathrm{T}_{\max }$ were shifted to higher temperatures, indicating a substantial increase of the CAP's thermal stability and a higher degree of compatibility.

\subsection{Differential Scanning Calorimetry (DSC)}

Figure 3 shows the DSC curves of the PET/PENTE, CAP and CAP (90/10). The oligomer showed $\mathrm{T}_{\mathrm{g}}$ around $61^{\circ} \mathrm{C}$. The CAP presented a thermal transition in the vicinity of $13^{\circ} \mathrm{C}$. All mixtures revealed the same transitions but that attributed to the $\mathrm{T}_{\mathrm{g}}$ of the oligomer shifted to a lower temperature $\left(43^{\circ} \mathrm{C}\right)$. This corroborated the high

Table 1. TG/DTG of the materials.

\begin{tabular}{ccccc}
\hline \multirow{2}{*}{ Samples } & \multicolumn{2}{c}{$\begin{array}{c}\text { Degradation } \\
\text { temperatures }\left({ }^{\circ} \mathrm{C}\right)\end{array}$} & $\begin{array}{c}\mathrm{T}_{\max } \\
\left({ }^{\circ} \mathrm{C}\right)\end{array}$ & $\begin{array}{c}\text { Residue } \\
(\%)\end{array}$ \\
\cline { 2 - 5 } & $\mathrm{T}_{\text {onset }}$ & $\mathrm{T}_{\text {end }}$ & & \\
\hline PET/PENTE 60/40 & 125 & 495 & $127 / 285 / 476$ & 9.22 \\
CAP & 258 & 500 & 441 & 14.1 \\
CAP (95/5) & 238 & 488 & 448 & 0.03 \\
CAP (90/10) & 250 & 490 & 453 & 11.9 \\
CAP (80/20) & 281 & 496 & 448 & 11.3 \\
\hline
\end{tabular}




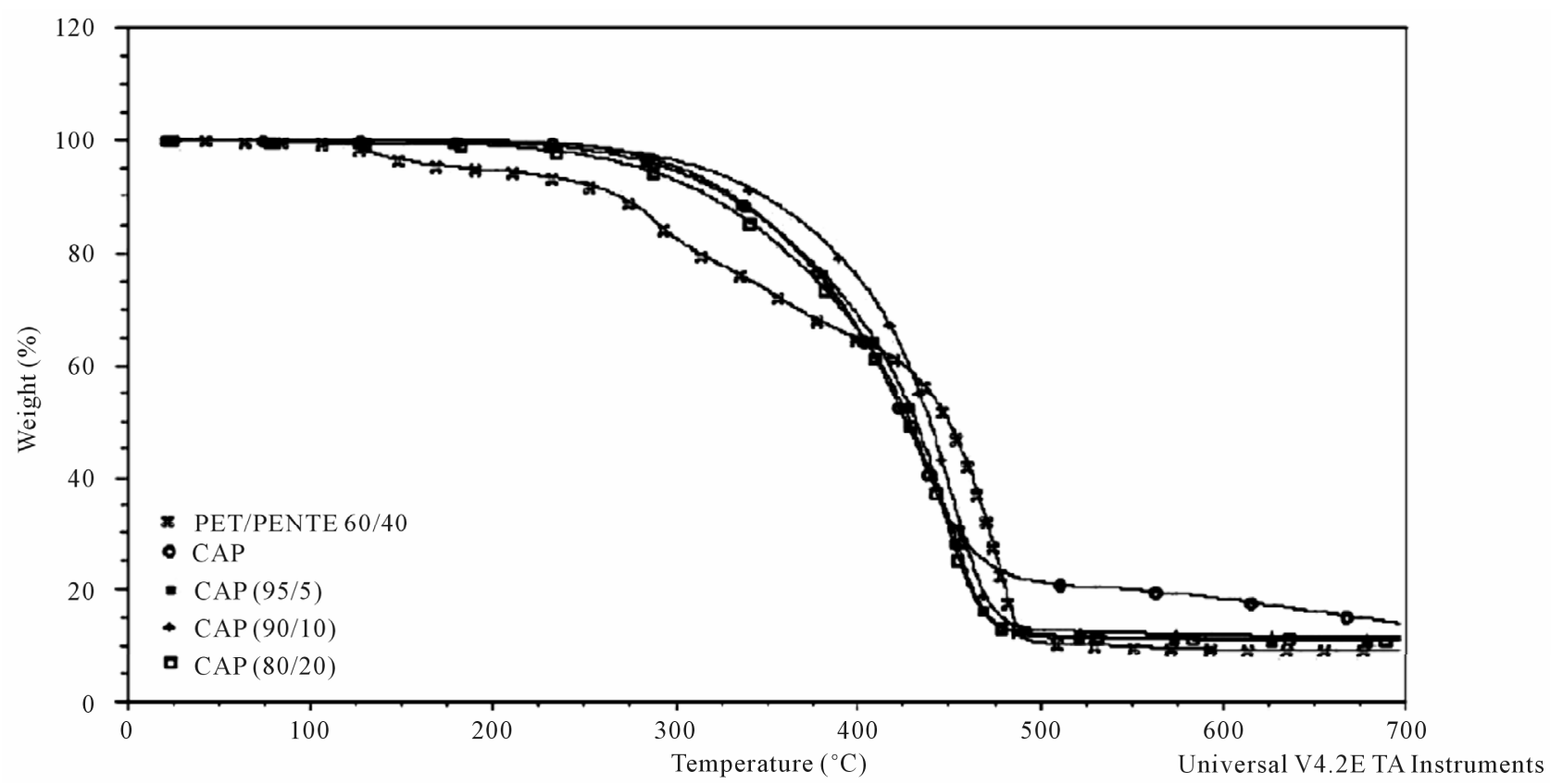

Figure 1. TG curves of the materials.

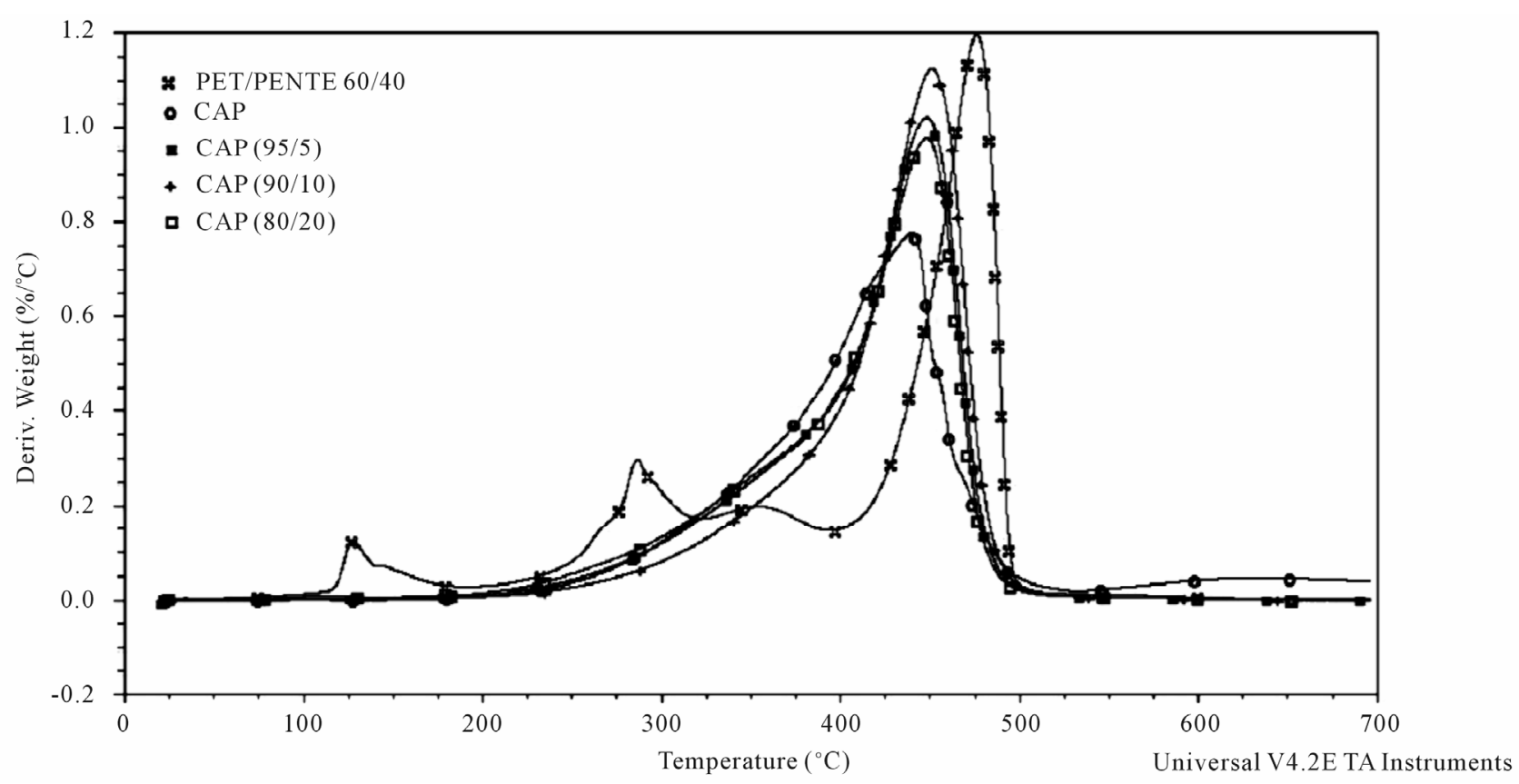

Figure 2. DTG curves of the materials.

degree of compatibility observed in the TG/DTG analysis.

\subsection{Units Morphological Analysis}

The photomicrographs of the CAP (Figure 4) and CAP/ Oligomer mixture (Figure 5) show the morphology of the materials in the solid and molten states. The CAP's images are similar and represent a heterogeneous mixture.
The crystalline phase-disperse droplets is embedded in the amorphous phase.

The CAP (95/5) photomicrographs did not reveal any phase separation. This might have occurred because of the total dissolution of CAP inside the oligomer matrix. In the mixtures with oligomer content higher than $5 \%$, the oligomer induced the fragmentation of the crystalline domains. There is a sharp phase separation. The matrix is formed by oligomer and the CAP amorphous phase. The 


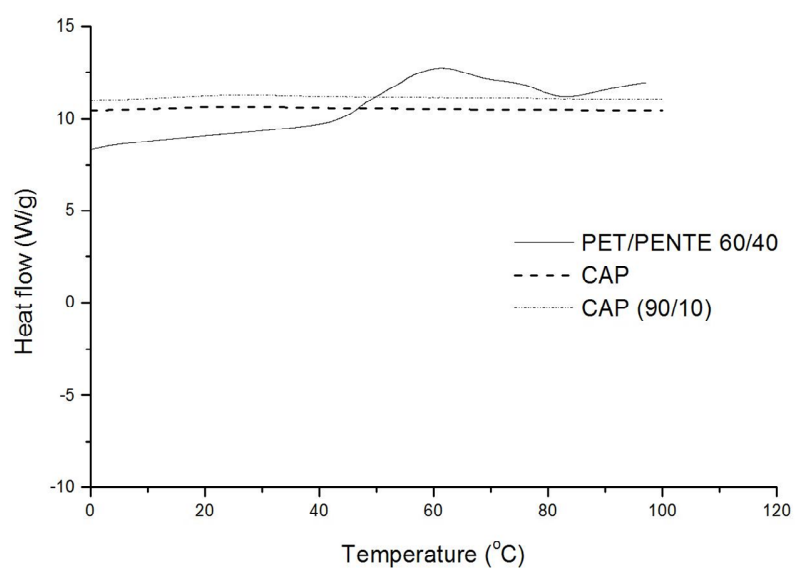

Figure 3. First heating DSC curves of the materials.

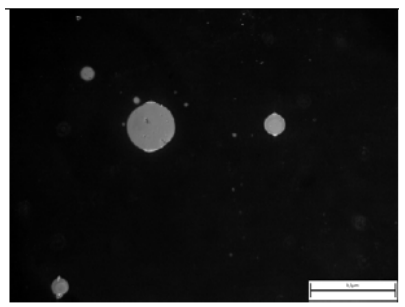

(a)

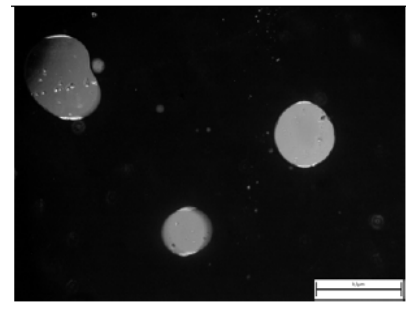

(b)
Figure 4. Optical fotographs. CAP: (a) Molten state; (b) Solid state.

crystalline phase appeared as dispersed small droplets.

\subsection{Peel Test}

Figure 6 shows the force required immediately before complete separation of the aluminum plates. For the mixtures, even taking into account the experimental errors, the values of the force were similar, independent on the oligomer content. The mixtures presented behavior similar to that of a ductile material.

Figure 7 shows the surface of the aluminum plates after the peel test. The CAP image revealed voids on the surface, indicating poor adhesion. For all mixtures, the oligomer improved adhesion. All surfaces were completely coated, showing cohesive fracture of the asphaltic mixture. The results indicated that the presence of the oligomer increases the resistance to disaggregation and durability of the asphaltic mixture, making it more suitable for paving.

\section{Conclusion}

In order to produce a new material from plastic waste, PET was oligomerized by a polyfunctional alcohol and mixed with CAP. The asphaltic mixture was characterized by several techniques. The DSC showed there is excellent compatibility between the constituents. The

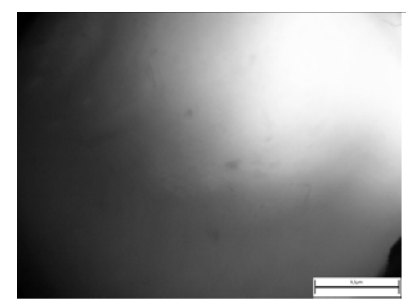

(a)

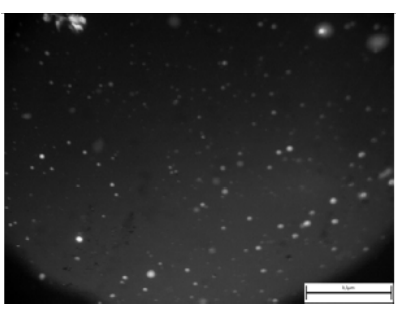

(c)

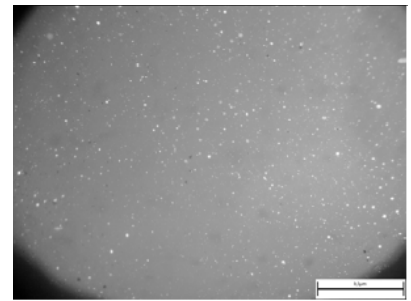

(e)

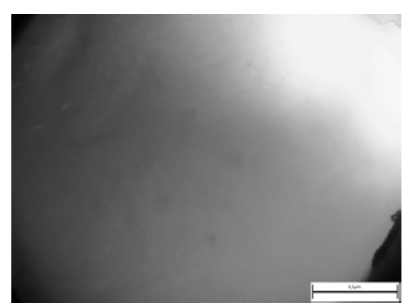

(b)

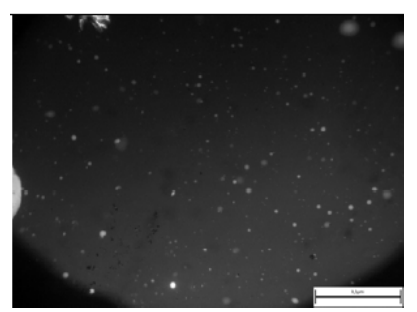

(d)

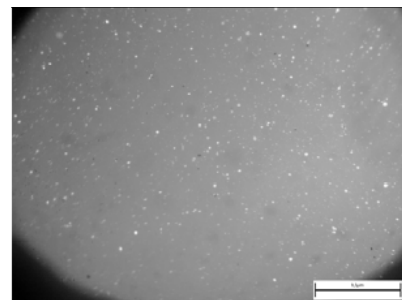

(f)
Figure 5. Optical fotographs of CAP/oligomer mixture. CAP (95/5): (a) Molten state; (b) Solid state; CAP (90/10): (c) Molten state; (d) Solid state; CAP (80/20): (e) Molten state; (f) Solid state.

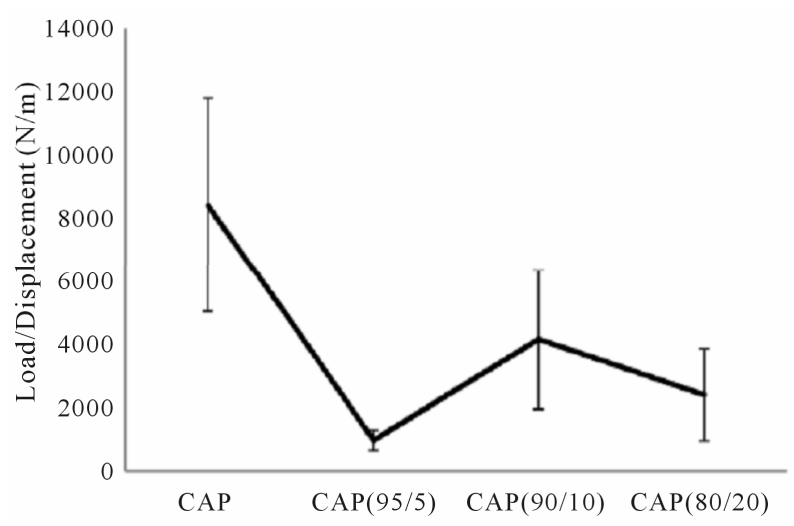

Figure 6. Pell test of the materials.

presence of the oligomer enhanced the CAP's thermal stability. Morphologically, in the mixtures, PET was the matrix and the CAP crystalline phase appeared as disperse domains. The mixture presented cohesive fracture and ductile behavior from the peeling evaluation.

\section{Acknowledgements}

The authors thank Fundação Coordenação do Aperfeiçoamento de Pessoal de Nível Superior (CAPES) and 


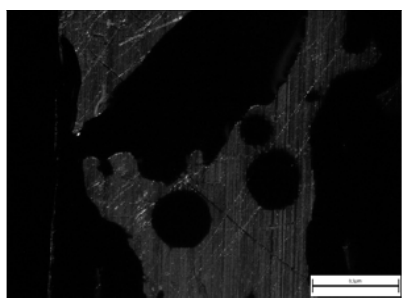

(a)
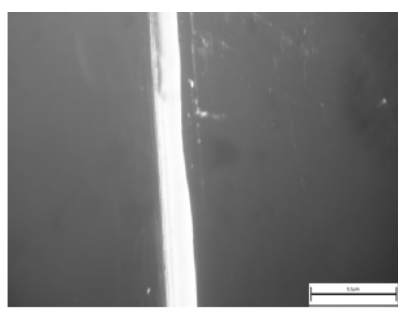

(c)

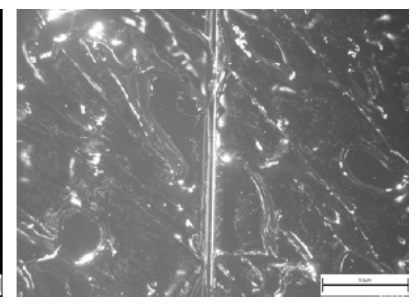

(b)

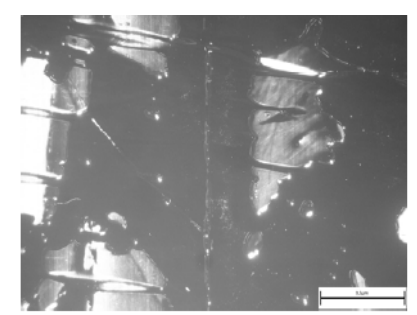

(d)
Figure 7. Surface of the aluminum plates after the peel test: (a) CAP; (b) CAP (95/5); (c) CAP (90/10); (d) CAP (80/20).

Universidade Federal do Rio de Janeiro (UFRJ) for supporting this investigation.

\section{REFERENCES}

[1] V. Sinha, M. Patel and J. Patel, "Pet Waste Management by Chemical Recycling: A Review," Journal of Polymers and the Environment, Vol. 18, No. 1, 2010, pp. 8-25. doi:10.1007/s10924-008-0106-7

[2] C. Piotr, "Synthesis and Modification of Epoxy Resins Using Recycled Poly(Ethylene Terephthalate)," Polymers for Advanced Tecnologies, Vol. 20, No. 3, 2008, pp. 183193.

[3] I. B. Grudnikov, E. V. Ippolitov and Y. I. Grudnikova, "Asphalt Production Technology. From Engineering Art to Science," Chemistry and Technology of Fuels and Oils, Vol. 40, No. 6, 2004, pp. 370-381. doi:10.1007/s10553-005-0004-9

[4] M. C. C. Lucena, S. A. Soares and J. B. Soares, "Characterization and Thermal Behavior of Polymer-Modified Asphalt," Materials Research, Vol. 7, 2004, pp. 529-534. doi:10.1590/S1516-14392004000400004

[5] A. S. Shirkunov, V. G. Ryabov, A. V. Kudinov, A. N. Nechaev and A. S. Degtyannikov, "Correlation of the Adhesive Properties of Petroleum Paving Asphalts and High-Melting Paraffin Content," Chemistry and Technology of Fuels and Oils, Vol. 47, No. 1, 2011, pp. 48-52. doi:10.1007/s10553-011-0255-6

[6] M. G. Morales, P. Partal and F. J. Navarro, "Viscous Properties and Microstructure of Recycled EVA Modified Bitumen," Fuel, Vol. 83, No. 1, 2004, pp. 31-38. doi:10.1016/S0016-2361(03)00217-5

[7] C. A. Cáceres and S. V. Canevarolo, "Scission in the Thermo Mechanical Degradation of Polystyrene under Multiple Extrusions," Polímeros, Vol. 18, 2008, pp. 348-
352.

[8] L. C. Mendes, M. L. Dias and T. C. Rodrigues, "Chemical Recycling of PET Waste with Multifunctional Pentaerythrytol in the Melt State," Journal of Polymers and the Environment, Vol. 19, No. 1, 2011, pp. 254-262. doi:10.1007/s10924-010-0276-y

[9] H. Jin, G. Gao and Y. Zhang, "Improved Properties of Polystyrene Modified Asphalt through Dynamic Vulcanization," Polymer Testing, Vol. 21, No. 6, 2001, pp. 633-640. doi:10.1016/S0142-9418(01)00135-0

[10] X. Lu and U. Isacsson, "Modification of Road Bitumens With Thermoplastic Polymers," Polymer Testing, Vol. 20, No. 1, 2001, pp. 77-86. doi:10.1016/S0142-9418(00)00004-0

[11] X. Lu and U. Isacsson, "Influence of Styrene-ButadieneSty-Rene Polymer Modification on Bitumen Viscosity", Fuel, Vol. 76, No. 14-15, 1997, pp. 1353-1359. doi:10.1016/S0016-2361(97)00144-0

[12] S. Alonso, L. M. Torres, R. Zitzumbo and F. Avalos, "Rheology of Asphalt and Styrene-Butadiene Blends," Journal of Materials Science, Vol. 45, No. 10, 2010, pp. 2591-2597. doi:10.1007/s10853-010-4230-0

[13] L. M. C. Cavalcante, S. S. Aguiar and S. J. Barbosa, "Characterization and Thermal Behavior of PolymerModified Asphalt," Materials Research, Vol. 7, 2004, pp. 529-534. doi:10.1590/S1516-14392004000400004

[14] M. C. Brum and M. L. Dias, "Processo de Produção de Asfalto Modificado," Brasileira Patent No. 0601920-0, 2006.

[15] M. C. Brum, M. L. Dias and C. R. Nascimento, "Processo de Obtenção de Oligômeros de Poli(Tereftalato de Etileno)," Brasileira Patent No. 0605201-0, 2006.

[16] U. L. F. Isacsson and X. Lu, "Characterizaion of Bitumens Modified with SEBS, EVA and EBA Polymers," Journal of Materials Science, Vol. 34, No. 15, 1999, pp. 3737-3745. doi:10.1023/A:1004636329521

[17] P. S. C. Pereira, L. C. Mendes, L. Sirelli and M. L. Dias, "Influence of Cobalt Complex on Thermal Properties of Poly(Ethylene Terephthalate)/Polycarbonate Blend," Journal of Thermal Analysis and Calorimetry, Vol. 87, No. 3, 2007, pp. 667-671. doi:10.1007/s10973-006-7873-y

[18] P. S. C. Pereira, L. C. Mendes and R. E. R. Abrigo, "Changes in Properties of PET/PC Blend by Catalyst and Time," International Journal of Polymeric Materials, Vol. 57, No. 5, 2008, pp. 494-505. doi:10.1080/00914030701816045

[19] L. C. Mendes and P. S. C. Pereira, "Optical Microscopy AS A Tool to Correlate Morphology and Thermal Properties of Extruded PET/PC Reactive Blends," Materials Sciences and Applications, Vol. 99, No. 2, 2011, pp. 1033-1040. doi:10.1007/s10973-009-0211-4

[20] ASTM D1876-08, "Standard Test Method for Peel Resistance of Adhesives (T-Peel Test)," Annual Book of ASTM Standards, 1995. 